\title{
Hacia una extensión rural fundada en el diálogo sinérgico de saberes: campesinos y extensionistas construyendo juntos
}

\author{
Marlon Javier Méndez Sastoque \\ Universidad de Caldas - Manizales - Caldas - Colombia \\ ORCID: https://orcid.org/0000-0003-4706-8136
}

\begin{abstract}
Resumen
Como contribución a la discusión actual entorno a la extensión rural y sus enfoques, desde una perspectiva crítico-analítica, el artículo debate sobre un tema principal: la necesidad de avanzar hacia una extensión rural fundada en el diálogo sinérgico y la acción concertada entre campesinos y extensionistas rurales, bajo condiciones de horizontalidad epistémica. Confrontando los enfoques vertical y dialógico, corrientes entre las que oscila la práctica extensionista, se plantean tres ejes básicos de análisis: a) las diferencias entre trasferir tecnología y co-construir conocimientos para la resolución de problemas situados, b) el reconocimiento de la complementariedad entre los saberes científico y campesino, y c) el diálogo de saberes como vía para plantear y de dar respuesta a objetivos comunes. Se concluye que conjugar múltiples sistemas de conocimiento, el científico y el campesino, en este caso, contribuye a potenciar el acervo cognitivo hoy socialmente disponible para responder a situaciones problemáticas agrarias de diferente índole.
\end{abstract}

Palabras clave: Extensión rural. Extensión dialógica. Conocimiento campesino. Desarrollo rural.

Towards a rural extension based on the synergistic dialogue of knowledge: peasants and extension agents building together

\section{Abstract}

As a contribution to the current discussion about rural extension and its approaches, from a critical-analytical perspective, the article discusses a main theme: the need to move towards a rural extension based on synergistic dialogue and concerted action between farmers and rural extensionists, under conditions of epistemic horizontality. Confronting the vertical and dialogic approaches, trends between which the extensionist practices oscillates, three basic axes of analysis are proposed: a) the differences between transferring technology and coconstructing knowledge to solve situated problems, b) the recognition of the complementarity between scientific and peasant knowledge, and c) the dialogue of knowledge as the basis for joint and concerted action. It is concluded that combining multiple knowledge systems, the scientist and the peasant, in this case, contributes to strengthening 
the cognitive store today socially available to respond to agrarian problematics situations of different nature.

Keywords: Rural extension. Dialogic extension. Peasant knowledge. Rural development.

\section{Rumo a uma extensão rural baseada no diálogo sinérgico de saberes: agricultores e extensionistas construindo juntos}

\section{Resumo}

Como contribuição para a discussão atual sobre extensão rural e suas facetas, em uma perspectiva crítico-analítica, o artigo discute um tema principal: a necessidade de avançar em direção a uma extensão rural baseada no diálogo sinérgico e nas ações concertadas entre camponeses e extensionistas rurais, sob condições de horizontalidade epistêmica. Confrontando as abordagens vertical e dialógica, correntes entre as quais a prática extensionista oscila, três eixos básicos de análise são propostos: a) as diferenças entre a transferência de tecnologia e a co-construção de conhecimento para resolver problemas locais; b) o reconhecimento da complementaridade entre o conhecimento científico e camponês; e c) o diálogo do conhecimento como base para a ação conjunta e acordada. Conclui-se que a combinação de múltiplos sistemas de conhecimento, neste caso o cientista e o camponês, contribui para fortalecer a herança cognitiva hoje socialmente disponível para responder a situações problemáticas agrárias de diferente natureza.

Palavras-chave: Extensão rural. Extensão dialógica. Conhecimento camponês. Desenvolvimento rural.

\section{Introducción}

Para quienes somos próximos a la extensión rural, incluyendo a quienes la hemos asumido como objeto específico de estudio, es común observar cómo las relaciones entre extensionistas y "usuarios de los servicios de extensión", principalmente miembros de comunidades campesinas, oscilan entre la imposición y el diálogo. Así, mientras para algunos equipos de extensión promover la adopción de lo externamente predispuesto es su principal labor, para otros, concertar junto con las comunidades lo que hay qué hacer y cómo hacerlo constituye su guía para la acción. No obstante, a pesar de su coexistencia, la balanza suele inclinarse a favor del primer estilo. En términos generales, actuar en pro de las comunidades campesinas no siembre va ligado a actuar junto con las comunidades campesinas, circunstancia que desconoce a sus miembros en su condición de sujetos pensantes y actuantes, otorgándoles el rol de simples objetos demandantes de asistencia social.

Bajo esta mirada, el objetivo de este artículo es presentar una propuesta de lectura crítico-analítica de la extensión rural hoy, centrando la atención sobre uno de sus pilares problemáticos más notables: la necesidad de avanzar hacia una extensión fundada en el diálogo sinérgico y la acción concertada entre campesinos y extensionistas rurales, bajo condiciones de horizontalidad epistémica. Para cumplir con el propósito planteado se hizo un ejercicio de confrontación de enfoques (enfoque vertical predominante vs. enfoque horizontal alternativo), ensayado alrededor de tres ejes temáticos: a) entre trasferir tecnología y co-construir conocimientos, b) de la negación del saber del otro al diálogo constructivo de saberes, y c) entre la imposición y el diálogo sinérgico alrededor de objetivos comunes. Lo expuesto resulta de la reflexión sistemática sobre la realidad empírica enfrentada por los extensionistas rurales en su práctica cotidiana, en esta ocasión 
leída desde la teoría. Disertación derivada del programa de investigación titulado "Dialogo permanente con extensionistas rurales: por una extensión en contexto", dirigido por el autor y financiado por la Vicerrectoría de Investigaciones y Postgrados de la Universidad de Caldas, Colombia.

Manteniendo la noción de unidad, el primer eje sintetiza las bases de los enfoques contrapuestos, vertical-transferencista y horizontal-dialógico, destacando sus principales matices. Muestra cómo el enfoque vertical, afín a un modelo modernizador-desarrollista, se centra en promocionar el cambio de lo atrasado a lo moderno, sustituyendo el conocimiento campesino por el técnico-agronómicocientífico, siendo la labor del extensionista promover dicha transformación cultural que niega la existencia de otros tipos de saberes y otras formas de concebir el desarrollo. Lectura confrontada por el enfoque horizontal, que reivindica la existencia de otros tipos de saberes y otras formas de pensar el desarrollo, oponiéndose a su rendición frente a las versiones dominantes. En este caso, promover el intercambio y el diálogo de saberes alrededor de hacia dónde y cómo avanzar en términos del desarrollo rural constituiría la labor de extensionista.

El segundo eje, conectado con lo anteriormente dicho, posiciona a la extensión convencional como instrumento para "modernizar el campo", intención asociada a industrializar la agricultura, igual que el pensamiento de los productores campesinos. Instaurar impositivamente entre ellos un modelo mental-actitudinal que les permita avanzar hacia su modernización (ser productivos, competitivos y eficientes en función de su inmersión en la economía capitalista de mercado) sería la función de la extensión rural. Alternativamente, en oposición a un proyecto unívoco de desarrollo, la extensión horizontal se presenta como la vía para que los actores rurales, principalmente aquellos en condición de desventaja, eleven sus capacidades para transformar y construir la realidad según sus formas de concebir el bienestar. Afín a este propósito, en vez de imponer una forma de ser, pensar y actuar, contribuir a elevar la autonomía de los campesinos y otros actores rurales, poniendo sus saberes en diálogo con los de ellos, en aras de definir qué hacer y cómo hacerlo, sería la función de los extensionistas rurales.

El tercer eje, apartado en el que se toma partida por el enfoque alternativo de extensión, llama a reconocer que, efectivamente, en un proceso de diálogo horizontal de saberes, los conocimientos campesinos y técnico-científico pueden interactuar complementándose, acción de la que pueden derivar ideas y propuestas innovadoras conjuntamente elaboradas. Igualmente convida a ser más conscientes de que del conocimiento campesino han surgido y continúan hoy aflorando soluciones a diversas problemáticas, alternativas de las que el conocimiento técnicocientífico y la sociedad en general se han beneficiado. Situación que, en términos de una extensión horizontal, invita a reconocer a los productores campesinos como generadores continuos de conocimientos e innovaciones tecnológicas, así como a superar la visión que los sitúa como simples receptores de lo dicho, planeado y concebido por otros.

Se espera que este documento despierte del interés de extensionistas y otros profesionales comprometidos con el mundo rural, contribuyendo a problematizar lo concerniente a la extensión rural y sus enfoques. 


\section{Entre trasferir tecnología y co-construir conocimientos: de la verticalidad a la horizontalidad en la extensión rural}

Sustentado en lo expuesto por Alemany y Sevilla (2006), podría plantearse que en la historia de la extensión rural han aflorado dos tendencias o trayectorias principales: la definida a partir de la mirada convencional y la surgida a partir de posturas alternativas.

Históricamente, la extensión convencional nace como una propuesta de intervención social dirigida a modernizar e industrializar tanto la agricultura como las sociedades rurales, soportada en trasferir a los productores agrícolas las tecnologías modernas creadas en los centros e institutos de investigación. Su trasfondo práctico e ideológico se centra en crear las condiciones que permitan a las sociedades tradicionales proseguir hacia la transformación del campo y sus formas habituales de vida, mediante la industrialización de sus prácticas agroproductivas (ALEMANY y SEVILLA, 2006; LELIS, COELHO Y DIAS, 2012). En esta línea, que los productores adopten la lógica moderna sería el camino para posicionar la agricultura industrial como forma única y legítima de producción en los espacios rurales (ALEMANY y SEVILLA, 2006).

En referencia a la práctica extensionista, remitiéndonos a sus orígenes, la concreción de dicha idea se soporta en la difusión de innovaciones tecnológicas (ROGERS, 1962, 1964), estrategia en sus fundamentos alineada con el enfoque modernizador de desarrollo. Paradigma, según el cual, el desarrollo se concibe a partir del tránsito de las sociedades tradicionales, en este caso rurales, a modernas (TOMMASINO et al, 2006), paso alcanzable a partir del cambio de las formas arcaicas de pensar y actuar, incluyendo la adopción de nuevas tecnologías para la producción agropecuaria. Bajo la influencia de la sociología rural norteamericana (LERNER, 1958; ARNOLD, 1966; BERNSTEIN, 1971) e inicialmente impulsada por el gobierno de los Estados Unidos como alternativa de desarrollo para los países "tercermundistas", esta tendencia ha procurado impulsar "cambios en la mentalidad conservadora y atrasada de los agricultores" con el fin de introducirlos en la "civilización científica" y permitirles "salir de su atraso" (ALEMANY y SEVILLA, 2006, p. 6).

Siguiendo esta directriz, en toda América Latina se expandió lo que todavía hoy podría llamarse "el afán modernizador-desarrollista". Tendencia cuyos marcos teóricos y guías prácticas indican la necesidad de modernizar a los campesinos e industrializar el manejo de la naturaleza. Propósito alcanzable mediante la incorporación de conocimiento científico, capital financiero e insumos externos principalmente derivados de la industria petroquímica, así como a partir de la adopción de una nueva lógica de pensamiento guiada por los valores predominantes en los países del norte (FUENTES, 2005). Bajo este impulso, valores como el "objetivismo, el empirismo estadístico, la neutralidad valorativa y la asepsia ideológica" (MURGA y BOILS, 1979, p. 18), a los que más contemporáneamente se suman otros ligados a la economía capitalista de mercado (eficiencia, eficacia, competitividad y pensamiento empresarial), deberían orientar el avance hacia una práctica agrícola moderna.

Sin embargo, a pesar de que esta línea aún se mantiene activa y fuerte, desde los años 60 y 70, otras miradas y modelos surgieron a la par, dando espacio a la alternatividad. Entre ellos destaca, sin ser la única, la propuesta de Extensión Rural 
Crítica (ERC), fundada en el pensamiento de Freire (1973) y la incorporación reflexiva de los aprendizajes derivados de múltiples experiencias de investigación-acciónparticipativa (IAP) y educación popular (FALS BORDA y BRANDÃO, 1987; FALS BORDA y ANISUR, 1991). Surgido del propio pensamiento latinoamericano, una de las características distintivas de este enfoque "es la forma colectiva en que el conocimiento se produce y se colectiviza (FALS BORDA y BRANDÃO, 1987, 18)", rompiendo el esquema, según el cual, el conocimiento es posesión de alguien que verticalmente lo transfiere o transmite a los otros.

De acuerdo con esta lectura, más que transferirse en su condición de verdad y discernimiento acabado, en una relación en la que el poseedor del saber lo extiende a quien no lo tiene, el conocimiento se construye a partir del diálogo horizontal y el intercambio de saberes entre quienes crean y experimentan la realidad concreta. En este orden, la labor extensionista tendría como acciones principales:

* Contribuir a problematizar la realidad, es decir, a comprender y entender los problemas enfrentados, explorando, en contexto, sus múltiples aristas.

* Poner en diálogo las distintas perspectivas acerca de la situación problemática congregante y dar valor al poder explicativo de cada forma de ver las cosas.

* Fomentar la búsqueda conjunta de soluciones (tecnológicas y demás) basadas en el conocimiento colectivamente generado sobre el problema que se enfrenta, seguido de concertar las opciones a poner a prueba.

Así, la ERC, próximo a los postulados de la IAP, tendría como objetivo transformar la realidad, dando lugar a "un proceso dialéctico continuo en el que se analizan los hechos, se contextualizan los problemas, se planifican y ejecutan conjuntamente las acciones en procura de transformar los contextos y circunstancias de vida (CALDERÓN y LÓPEZ, 2013, p. 59)", como base de un proceso (acción consciente) de formación para la transformación social.

En este escenario, la extensión rural alternativa tendría como pilar fundamental fomentar la participación para el cambio y la reflexión social. Con la posibilidad de actuar como iguales, los actores agregados en torno a un asunto rural buscarían respuestas a situaciones críticas de índole económica, política, tecnológica o socioambiental, en un contexto de diálogo en el que la palabra verdadera no es el privilegio de unos que la verbalizan para otros (RODRíGUEZ et al, 2007), sino, por el contrario, el resultado del intercambio creativo de saberes, ideas y miradas con fines transformadores, premisa que orientaría el avance hacia una extensión rural fundada en el diálogo sinérgico de saberes.

En esta ocasión, se asume como actores con potencial de acción conjunta a campesinos y extensionistas rurales, quienes, en reconocimiento de sus capacidades mutuas de aportes, podrían aunar esfuerzos, conocimientos y experticias alrededor de objetivos comunes. Práctica que, como se desarrollará a lo largo del artículo, requiere, entre las principales acciones, derrumbar las barreras culturalmente construidas entre los conocimientos campesino y científico, fomentar el diálogo intercultural y de saberes entre productores y extensionistas, acciones asumidas 
como bases para avanzar hacia un modelo dialógico u horizontal de extensión, asunto a continuación desarrollado.

\section{De la negación al diálogo sinérgico: sumar antes que sustraer frente a la búsqueda de alternativas de desarrollo agrícola y rural}

Analíticamente, podría plantearse que, en el marco de la extensión convencional-difusionista, la función a cumplir por los extensionistas rurales sería, en síntesis, contribuir a la modernización de la agricultura y los agricultores, bajo una mirada que califica a los actores rurales (campesinos y pequeños productores, principalmente) como tradicionales y premodernos, cuando no como atrasados e ignorantes. En este contexto, contribuir a que ellos sustituyan el saber y las prácticas tradicionales por otras fundadas en el conocimiento científico sería su principal papel, siendo servir como intermediarios entre el productor (adoptante de tecnología) y las universidades, centros de investigación y casas comerciales (generadores de tecnología) la actividad extensionista más significativa.

Trasferir linealmente tecnología sería, en este caso, la función primordial, en la medida en que este constituiría el camino para moderniza, industrializar y "empresarizar" la agricultura. En la práctica, retomando lo expuesto por otros autores, tareas como las siguientes serían la base de la extensión agrícola:

Introducir nuevos conocimientos técnicos y científicos en las áreas rurales con el fin de generar cambios y mejorar la calidad de vida de los agricultores y sus familias, seguido de garantizar que la información sobre nuevas tecnologías, variedades de plantas y prácticas culturales lleguen a esos agricultores (PAVÓN, 2014, p. 6).

Hacer llegar información o tecnología útil a la población [rural] y ayudarla a adquirir conocimientos, habilidades y actitudes necesarias para aprovechar eficazmente el conocimiento científico para el desarrollo productivo (PARDO, 2008, p. 72)

Elevar los rendimientos y mejorar la calidad de los cultivos y, para el caso de la ganadería, aumentar la productividad y mantener la sanidad de los hatos ganaderos, de manera que ello contribuya a mejorar la economía de los productores (FERNÁNDEZ et al, 2009, p. 735), a partir de la introducción de nuevas prácticas y tecnologías.

Apoyar a los productores agropecuarias en el desarrollo de sus competencias empresariales y fomentar [su incursión en] proyectos productivos que impliquen el desarrollo de competencias relacionadas con ser emprendedor (FIGUEROA y RODRÍGUEZ et al., 2010, p. 355).

En este contexto, si se asume que la función central de los extensionistas es transferir tecnología para modernizar la agricultura, la extensión giraría en torno a convencer y persuadir a los miembros de las comunidades campesinas a adoptar prácticas productivas y valores afines a dicho propósito. Apropiando lo expuesto por Beltrán (1981), siguiendo el paradigma clásico de la comunicación en extensión, la intención del extensionista sería inducir, en determinada dirección, el comportamiento del receptor (campesino-productor), logrando afectar sus formas 
de pensar, sentir y actuar, a favor del cambio que se quiere introducir: su modernización.

En esta vía, estudiar los modos de pensar, sentir y actuar de los usuarios y potenciales adoptantes de las tecnologías, con el posterior propósito de tener criterios clave para definir cómo inducir la valoración positiva y la adopción de las tecnologías o ideas impulsadas por las agencias promotoras del desarrollo agrícola, haría parte de la labor cotidiana de los extensionistas rurales. Saber qué decir, cómo decirlo, cuándo hacerlo y qué canal utilizar para expresarlo, entre otras tácticas de convencimiento, sería un aprendizaje útil para el transferencista de tecnología. Actuación analíticamente amparada en un modelo vertical y unidireccional de extensión, donde el emisor del mensaje tendría casi poder absoluto sobre el receptor, personaje idealmente asumido como manipulable y pasivo (KRÖNLING, 2000).

Desde otro ángulo, cumplir con la función atribuida también le implicaría a los extensionistas rurales aprender y aceptar, en tiempos de hoy, algunos postulados del modelo convencional. Adaptando lo expuesto ya hace varias décadas por Beltrán (1981), quien hace una crítica al paradigma modernizador, los supuestos a interiorizar (a manera de aprendizaje) serían los siguientes:

* Que el incremento de la producción, la productividad, el ingreso y el consumo de bienes por parte de los productores agropecuarios constituyen la esencia del desarrollo agrícola y rural.

* Que la vía suprema para aumentar la productividad y, por ende, alcanzar mejores condiciones socioeconómicas y de vida, es adoptar nuevas tecnologías y tecnificar, así, la producción.

Afín a estas ideas, el extensionista debería actuar en función de:

* Inducir en los agricultores la adopción de un nuevo modelo mental-actitudinal que les permita transitar de una economía campesina (pobre y de subsistencia) a una empresarial acorde con la economía capitalista de mercado, que los habilite para mantenerse en esta, competir con precio y calidad, reducir costos, aumentar ganancias, acumular y reproducir el capital (BORJA y CASTILLO, 2013).

* Conseguir que los agricultores "eliminen sus propias ineficiencias para aumentar sus actuales rendimientos", poniéndose a la par de los grandes productores a nivel mundial. Cómo organizarlos con fines empresariales. Lo cual incluye convencerlos para que se asocien y con ello aumenten su escala económica, sean eficientes y consigan, por fin, "salir del subdesarrollo en el cual están" (PEÑARANDA, 2010, p. 240).

Como opción a lo anterior, la función social de la extensión alternativa, por encima de promover entre "los más pobres del campo" la adopción de innovaciones tecnológicas que les permita, bajo un enfoque de inclusión competitiva (NISHIKAWA, 2016, p. 19), articularse a la economía de mercado, se centraría en contribuir a que los actores rurales, principalmente aquellos históricamente en desventaja, activen su 
potencial para trasformar la realidad. Transformación consistente en poder por sí mismos avanzar hacían donde desean o necesitan llegar, puntos de arribo coherentes con sus formas de figurar lo que para ellos significa estar y vivir bien (MÉNDEZ, 2016).

Así, en un medio social en el que abundan las asimetrías de poder, contribuir a que los miembros de las comunidades campesinas reivindiquen su lugar en la sociedad como un todo, logrando que ésta aprecie su existencia y valore (multidimensionalmente) su aporte al bienestar general, haría parte de la función social de la extensión rural alternativa. Papel idealmente a cumplirse en un contexto de respeto, aceptación y comprensión de sus formas autónomas de ser, sentir, pensar y actuar, en el que se rechace toda intención de hacer de ellos (al tratarlos como objetos manipulables) algo que no son o desean ser.

En este escenario, si la base de la extensión rural alternativa es contribuir a generar capacidades en la gente para poder, con autonomía y juicio crítico, transformar su propia realidad (económica, política, socioproductiva, ambiental), la labor a realizar por los extensionistas rurales giraría en torno a:

* Generar espacios conjugados para la reflexión-acción alrededor de la realidad vivida, bajo condiciones en que los individuos dejen de ser objetos y asuman el papel de sujetos de su propia historia, capaces de comprenderla, explicarla y transformarla (TOMASSINO et al., 2006). Lo cual incluiría, para el caso de los actores productivos (campesinos, pequeños productores y otros sujetos de los procesos de extensión), una vez analizada la realidad productiva, lograr incidir cada vez más en la definición de cómo, qué, para qué y para quién producir (FREIRE y FAÚNDEZ, 1985).

* Contribuir, junto con la gente, a fortalecer y elevar su autonomía en relación con la toma de decisiones (ALEMANY y SEVILLA, 2006), en procura de concertar y establecer formas de producción y consumo que ayuden a enfrentar la crisis ecológica y social actual. Problemática derivada de alterar el curso de la coevolución ecológica y social definidora de la cultura agrícola tradicional (NORGAARD, 1994), hoy recuperable a partir del diálogo del saber científico con el conocimiento local (campesino e indígena), en conjunto poseedores de claves para la potenciación de la biodiversidad ecológica y sociocultural (ALTIERI, 1997; GLIESSMAN, 1998).

* Promover procesos educativos, territoriales y endógenos de transformación social, ambiental, económica, productiva e institucional, mediante acciones colectivas dirigidas al desarrollo de sociedades sustentables (SEVILLAGUZMÁN y WOODEGATE, 1998; ALEMANY y SEVILLA, 2006). Desarrollo fundado en el respeto a los valores, los saberes y las culturas locales, el uso y la conservación de los recursos situadamente disponibles, la valoración de las formas autóctonas de consumo y distribución de lo localmente producido, sumado a la retención y partición equitativa de los beneficios obtenidos, bajo un enfoque que congruentemente articule lo interno con lo externo, logrando así fortificar los procesos locales (LONG y VAN DER PLOEG, 1994). 
* Movilizar a los actores sociales locales para estudiar su propia realidad, realizar diagnósticos, diseñar estrategias y promover proyectos encaminados a solucionar sus problemáticas, activando su capacidad de acción e innovación, el diálogo con otros actores y la participación ciudadana en torno a objetivos comunes (LIMIA, 2004; RODRíGUEZ et al, 2009).

* Revalorizar y revitalizar las sabidurías originarias campesinas, recuperando la vigencia de los valores y conocimientos ancestrales que aportan a la sustentabilidad alimentaria y el bienestar de la sociedad en general, promoviendo el diálogo horizontal entre distintos saberes, incluido el científico de la modernidad, en procura de encuentros y complementariedades (DELGADO, 2006; TAPIA, 2016, 104).

* Contribuir a que lo miembros de las comunidades rurales activen y desenvuelvan sus capacidades para "asumir de manera autónoma sus procesos de desarrollo o sus modos de estar y habitar en el mundo". Premisa sustentada en que los campesinos y productores, más que objetos de proyectos de asistencia técnica, son sujetos de conocimiento, fuente de poder necesaria para la emancipación social, enriquecida a partir de la integración horizontal de los saberes empíricos, tradicionales y científicos (TOBASURA, 2018).

En esta línea, en el marco de la extensión rural alternativa, preceptos a considerar crítica y reflexivamente por los extensionistas, a manera de aprendizaje o deliberación formativa, serían:

* Que el acervo cognitivo útil para la resolución de problemas y la lectura en contexto de realidades concretas (incluyendo las agroproducitvas) está integrado por múltiples conocimientos, diversos en su origen y fundamento. Conjunto en el que se incluyen los conocimientos y saberes tradicionales, locales y científicos, cada uno con igual validez y ubicación jerárquica.

* Que las personas con las que se interactúa son sujetos pensantes y actuantes, con capacidad crítica, observacional y propositiva, tomadores constantes de decisiones, con capacidad de actuar sobre su propia realidad, a quienes no se debe subestimar. Sujetos poseedores de conocimientos clave, con quienes se ha de dialogar, en igualdad de condiciones, en procura de salidas o soluciones concertadas.

* Que, pese a que somos distintos, unos campesinos y otros profesionales universitarios, unos formados en las aulas y otros directamente en los entornos agrícolas familiares, por ejemplo, dicha diferencia se disipa, al reconocernos mutuamente como expertos formados en diferentes contextos, cada uno poseedor de un saber incompleto (en construcción permanente) a compartir y complementar con el del otro. 
* Que la definición de hacia dónde avanzar, qué objetivos seguir, qué metas establecer, no puede ser precisadas por agentes externos. Son los miembros de las comunidades rurales quienes, según sus perspectivas de bienestar y desarrollo, deben decidir sobre ello.

Siguiendo esta mirada, si la extensión alternativa tiene como propósito básico contribuir a que los actores rurales, principalmente aquellos en condiciones históricas de desventaja, desarrollen capacidades y activen su potencial para transformar la realidad, siguiendo lo expuesto por Méndez (2016), los extensionistas deberían actuar en función de:

* Contribuir a que los actores rurales desenvuelvan habilidades para, políticamente, proteger y hacer valer sus derechos como ciudadanos del campo, reivindicar su posición social como productores de alimentos y actores socioeconómicos protagónicos en el mantenimiento de la seguridad y la soberanía alimentaria del país.

* Aportar a que los sujetos rurales, en medio de un contexto dominado por la manipulación política, desarrollen habilidades para la participación efectiva, tomando distancia de las presiones y dependencias clientelares, ganando autonomía y capacidad de decisión sobre los asuntos que son de su interés, al participar en espacios de concertación democrática.

* Coadyuvar a que dichos actores desarrollen habilidades para la comunicación dialógica u horizontal, aprendiendo a superar los poderes que los aminoran en su condición de sujetos, a hacer valer sus voces y miradas ante las de los otros, creando ambientes de igualdad fundados en la escucha multidireccional y la toma colectiva de decisiones.

Contribuir a dicho cambio les implicaría a quienes ejercer la labor extensionista a su vez formarse en:

* Cómo desatar, a partir de su práctica cotidiana, procesos colectivos de problematización de la realidad (considerando, por supuesto, la realidad agroproductiva) y la búsqueda colaborativa de soluciones. En otras palabras, cómo robustecer y ayudar a generar escenarios y mecanismos participativos de análisis de la realidad, que permitan entender e interpretar la naturaleza y trasfondo de los hechos que generan los problemas (SEVILLA-GUZMÁN, 2001), práctica preparatoria para la propuesta informada de acciones y el recuento de los recursos localmente disponibles para acometerlas.

* Cómo fomentar el diálogo horizontal de saberes, abrir la mente al saber y la perspectiva del otro (campesino), reconociendo su validez y valía en el contexto sociocultural de origen, en procura de soluciones concertadas integrales. Cómo abrirse al conocimiento de ese otro y ponerlo en diálogo con el conocimiento propio, aceptando que de la sabiduría tradicional, del conocimiento empírico generado de la relación próxima entre hombre y 
naturaleza, han derivado y continúan emanando tecnologías, prácticas agronómicas y culturales que pueden aportar significativamente al desarrollo agrícola y rural (TAPIA, 2006).

* Cómo obrar junto con el otro (el campesino, el pequeño productor, otros extensionistas formados en disciplinas distintas a las agropecuarias, como las ciencias sociales), uniendo fuerzas en torno a un objetivo común, superando el individualismo en el trabajo y la visión fraccionada de la realidad.

En resumen, podría plantearse que la función social atribuida a la extensión rural varía según el enfoque de extensión predominante. Cuando prevalece la visión modernizadora, transferir tecnología agrícola externamente diseñada es la función a cumplir por la extensión rural, con la intención de modernizar la agricultura y el pensamiento de los agricultores; quehacer fundado en la práctica impositiva y la comunicación unidireccional. No obstante, cuando prima la visión alternativa, actuar conjuntamente sobre la resolución de situaciones problemáticas es la vía principal a seguir, al aunar esfuerzos y generar sinergias a partir del intercambio intercultural de conocimientos y saberes. Acción soportada en el diálogo multidireccional y el reconocimiento permanente de los otros como seres pensantes y actuantes, sujetos creativos con capacidad de aportar a la resolución de circunstancias por ellos mismos enfrentadas, asunto tratado con más profundidad a continuación.

\section{Promoviendo el diálogo sinérgico: aunando conocimientos y saberes en respuesta a objetivos comunes}

En principio, promover el diálogo sinérgico entre extensionistas y campesinos implica, sobre todo para los primeros, aceptar y comprender la validez del conocimiento tradicional. Acciones concretadas, en gran medida, a partir de la aproximación comprensiva a la cotidianeidad campesina, al origen de sus conocimientos y a sus formas de concebir la efectividad de ese saber. Como argumenta Cruz-León et al (2015), la evidencia más sólida de la validez y la eficacia de este tipo de saberes se halla en la permanencia histórica de los grupos humanos en sus territorios. Gracias a la aplicación de ese saber, las comunidades campesinas han persistido hasta hoy, reproduciendo sus conocimientos de generación en generación. Conocimiento que no ha sido estático ni apegado a una sola cosmovisión (DÍAZ, ORTIZ y NÚÑEZ, 2005), sino constantemente abierto a lo nuevo, es decir, a aquello que ha resultado útil a sus formas de hacer agricultura y solucionar problemas de distinta índole, incluyendo el saber técnico compartido por los extensionistas rurales.

En síntesis, se trata de conocimientos múltiples, entre otros temas asociados a la conservación y el uso de los recursos naturales, al reconocimiento de especies silvestres aprovechables, a la diversidad genética existente en los diversos territorios, a las condiciones agroecológicas específicas de sus lugares habituales de siembra, a las técnicas y tecnologías desarrolladas in situ para su aprovechamiento y manejo, al diseño y uso de herramientas tradicionales y a las formas de trasmitir dichos conocimientos (CRUZ-LEÓN et al, 2015; PANIZO y PERDONO, 2017), que han de ser valorados e integrados a los procesos de búsqueda conjunta de soluciones a hechos problemáticos de interés común. Saberes y experiencias acumuladas a lo largo del 
tiempo, fruto de lo aprendido de generación en generación por hombres y mujeres rurales, mas también de lo aprendido día a día por sí mismos, a partir de su vivir y convivir con otros y el medio natural inmediato (TOLEDO, 2005; RODRÍGUEZMORENO, 2014; CAMARGO, DE SOUZA y DA COSTA, 2014), resultantes, entre otras vías, de la observación, la experimentación y la curiosidad constante.

Esta perspectiva, próxima al enfoque dialógico de la extensión, llama a concebir a los propios productores no solo como meros receptores del conocimiento suministrado por los profesionales agrícolas, sino como generadores permanentes de conocimientos y tecnologías endógenas. Como señalan Cáceres et al. (1997), las tecnologías adoptadas por los pequeños productores corresponden tanto a aquellas provenientes del exterior de sus unidades productivas (exotecnologías) como a aquellas generadas por ellos mismos como consecuencias de procesos de creación, experimentación y adaptación tecnológica (endotecnologías). Circunstancia que habla de su capacidad creativa, que se extiende más allá de lo únicamente agrícolatecnológico, al proyectarse sobre la resolución de múltiples situaciones a intervenir enfrentadas en la vida cotidiana, hecho sobre el que han de ser conscientes los extensionistas rurales.

En este contexto, siguiendo lo expuesto por Delgado y Rist (2016) alrededor del diálogo intercultural y de saberes, el principal desafío para la extensión y los extensionistas rurales sería encontrar la manera de fomentar el diálogo cooperativo y constructivo entre las partes, en condiciones en las que cada una (campesinos y extensionistas) horizontalmente contribuyan con sus saberes y experiencias al cumplimiento de los objetivos trazados. Ejercicio a realizarse en un escenario abierto en donde el acervo de conocimiento disponible (conocimiento tradicional campesino + conocimiento técnico-científico) se emplee a favor de los propósitos seguidos, en condiciones en que ninguna de las partes trate de imponer sus perspectivas. En esta línea, abrirse a la perspectiva del otro, saber bajo qué lógica hace sus apreciaciones para encontrarles sentido, ha de ser un ejercicio multidireccional, basado en la escucha activa y comprensiva.

Saber cómo el otro concibe el problema (cómo problematiza la realidad vivida), a qué atribuye las situaciones afrontadas, cuáles son las aristas en las que centra la atención y cómo valora el efecto derivado de intervenirlas o no, entre otros cuestionamientos primarios, podrían ser la base inicial del diálogo cooperativo y constructivo. Posteriormente, plantear propuestas de intervención, ponerlas en diálogo, argumentar posiciones, dirimir contradicciones e identificar complementariedades serían los pasos por seguir en aras de llegar a acuerdos. En esta dinámica, influenciar y dejarse influenciar, otorgándole sentido a lo expuesto por el otro, valorando su conveniencia y contraargumentado, cuando sea el caso, las ideas emergentes con las que no se está de acuerdo, permitiría llegar a arreglos concertados.

Bajo esta óptica, a diferencia de lo que pasa en la extensión difusionista (fundada en convencer a toda costa al otro para que adopte la solución predefinida externamente), influenciar al otro sería una actividad lícita, al no tener como fin manipular, sino, al contrario, aportar a construir conjuntamente desde lo propio. En este sentido, en medio del diálogo horizontal, la persuasión mutua haría parte integral de un modelo democrático, humanizado, no elitista y no mercantilizado de comunicación (BELTRÁN, 1981). Diálogo que participativamente coadyuvaría a 
elaborar lecturas crítico-analíticas de la realidad a estudiar o intervenir, así como a relativizar, cuando sea el caso, las posturas e ideas propias acerca de los asuntos y problemas conjuntamente abordados.

En esta vía, coincidiendo con lo expuesto por Pérez y Argueta (2011, p. 49), “la propia construcción de los debates y los problemas a resolver debería ser el resultado de un diálogo horizontal entre los portadores de diversos sistemas de conocimientos". Los propósitos, los métodos, así como los instrumentos a utilizar para su resolución, tendrían que elaborarse mediante el trabajo colectivo, previo a la "identificación de los puntos en los que los diferentes sistemas de conocimiento logren interactuar y articularse, sin suplantarse ni subordinarse uno a otro" (PÉREZ y ARGUETA, 2011, p. 49). Ejercicio que conlleva a reconocer y asumir que los conocimientos campesino y técnico-científico pueden interactuar con éxito. Que ambos tipos de conocimiento, pese a sus diferencias en relación con su origen y construcción, no son irreconciliables ni excluyentes (ALEMÁN, 2016), mas sí complementarios.

Dicha descubierta ha de incluir la certeza de que el conocimiento tradicional ha sido históricamente usado, creado y recreado para responder a los cambios del medio físico y social. Como es sabido, cambios de orden climático, agroecológico, político y socioeconómico ha suscitado a lo largo del tiempo la acomodación a las nuevas circunstancias y la generación de alternativas endógenas de adaptación y respuesta, estrategias que han de ser integradas al acervo disponible para enfrentar los desafíos del presente. A manera de ilustración, Altieri y Nicholls (2008), entre otros autores, exponen cómo las comunidades campesinas en América Latina y otras partes del mundo han generado, por su cuenta, respuestas adaptativas al cambio principalmente climático:

* Uso de la diversidad genética local. Uso de especies y variedades localmente adaptadas (criollas y tradicionales) resistentes al calor y la sequía, sumado a la siembra simultánea (en el mismo lote y al mismo tiempo) de diversas variedades de un mismo cultivo, como protección ante afecciones fitosanitarias.

* Diseño e implementación de estrategias de diversificación. Establecimiento de policultivos o sistemas de cultivos múltiples que exhiben mayor resistencia a las perturbaciones ambientales en comparación con el monocultivo. Siembra en arreglos agroforestales, usando la cobertura de los árboles como protección de los cultivos ante oscilaciones bruscas en el microclima y la humedad edáfica.

* Incremento del contenido de materia orgánica de los suelos. Ingenio de prácticas de rotación de cultivos, preparación de biocompost y abonos verdes, cobertura del suelo con residuos orgánicos como estrategias para el aumento de la producción de biomasa, contribuyendo al incremento de la materia orgánica en el suelo.

* Uso de mecanismos de regulación biológica para el control fitosanitario. Siembra de especies antagónicas y alelopáticas para la prevención de 
enfermedades y plagas, así como para reducir la infestación de malezas en los cultivos.

* Manejo del agua. Diseño de mecanismos para la captación y retención de agua a ser principalmente utilizada en épocas de sequía, sumado a arreglos para la prevención de erosión, lixiviado de nutrientes e inundaciones en periodos de lluvia intensa.

Tecnologías e innovaciones campesinas a las que se agregan otras asociadas a áreas como:

* Organización para el desarrollo local. Activación autónoma de las redes sociales existentes en los territorios y comunidades rurales alrededor de proyectos de índole económica, política o cultural, basada en la institucionalización de valores culturales compartidos como la solidaridad, la confianza, el respeto y la reciprocidad, en donde el éxito de la autoorganización se centra en la solidez de los lazos sociales históricamente construidos (GIRALDO, 2010).

* Gestión popular de bienes comunes. Propuesta y puesta en marcha de esquemas organizativos y administrativos para la gestión de recursos, como el agua potable y para riego, basados en el conocimiento local, la participación social y la democracia comunitaria, que elevan las condiciones de vida de las propias comunidades gestoras y procuran la sostenibilidad de los ecosistemas administrados (BARKIN, 2003; PIMENTEL-EQUIHUA et al, 2012).

En conjunto, se trata alternativas endógenamente surgidas, basadas en la aplicación en contexto del conocimiento local, que habrían de ser consideradas al momento de proponer conjuntamente opciones para solucionar problemas o aprovechar las potencialidades locales. En este escenario, reconocer plenamente estas capacidades (capacidad innovadora, creatividad y experticia campesina), sumado a ganar conciencia sobre la existencia de alternativas tecnológicas nacidas sin la directa influencia institucional externa, permitiría, al integrarlas a la búsqueda de soluciones, fortalecer el acervo disponible para la práctica transformadora tanto al interior como más allá de las fronteras de los sitios de origen. Conexamente, hacer un uso concertado de las habilidades, prácticas y saberes tradicionales, otorgándoles el debido valor en un proceso de diálogo horizontal con el conocimiento científico (en principio orientador del saber y las propuestas de los extensionistas), contribuiría a posicionar a las mismas comunidades rurales como planificadoras y cogestoras de su propio devenir. Modo de actuar en esencia generador de dinámicas sociocomunitarias en las que ellas mismas serían las ejecutoras y administradoras de los proyectos y programas surgidos. Autonomía que contaría con la complementación brindada por los extensionistas rurales.

En este escenario, como parte del diálogo intercultural y de saberes, sobre todo para los extensionistas y la institucionalidad construida alrededor del desarrollo agrícola y rural, coincidiendo con lo expuesto por Tapia (2006), comprender la forma en que los campesinos investigan y generan nuevo conocimiento (incluyendo sus 
racionalidades, sentidos y fuentes) es un paso requerido para la adaptación institucional en aras del trabajo conjunto, en la medida en que la investigación científica y la investigación campesina se hacen de manera diferente. De igual forma, manteniendo la idea de conocimiento en doble vía, compartir con los productores campesinos cómo se genera el conocimiento científico, cuáles son los procedimientos seguidos por los investigadores, cómo se validan los resultados o hallazgos obtenidos, tendría sentido en términos de "abrirse al otro", en miras a la complementación de prácticas y saberes. En este contexto, compatibilizar ambas formas, generar creativamente arreglos que permitan la investigación conjunta, sería uno de los principales retos. Acuerdo que, retomando lo expuesto por Samper (2005), deberían evitar la concepción de esquemas inflexibles que coarten la creatividad metodológica o aminoren la diversidad de formas de experimentar a una única.

En esta línea de valoración e integración del conocimiento campesino al acervo local disponible para la resolución de situaciones problemáticas, es preciso hacer la siguiente advertencia: para ser correctamente comprendidos, los saberes tradicionales y locales, entre los que se encuentra el saber campesino, deben analizarse y entenderse en el contexto cultural de origen (TOLEDO, 2005). Extraerlos de sistema sociocultural en el que adquieren sentido, desamparándolos de parte de las condiciones contextuales que les imprimen especificidad, conlleva al riesgo de aminorar su aplicabilidad. En otras palabras, apartar dichos conocimientos del contexto social que los soporta, fragmentando los lazos e interacciones existentes entre el saber endógeno y la cultura local, conduciría a aprehenderlos simplificada y parcialmente, con repercusiones posteriores sobre su replicabilidad en contextos diferentes.

A manera de ilustración, una tecnología endógena de cuidado del agua trasladada a un escenario en el que predomina la racionalidad utilitarista sobre el uso de los recursos naturales, en vez de la mirada vitalista persistente en su lugar de origen (el agua vista como fuente de vida), por ejemplo, podría apenas adoptarse o adaptarse parcialmente a las condiciones del primer contexto. Un endotecnología asociada a la fertilización orgánica, fundada en el respeto a la Madre Tierra y a la convicción de alimentarla para conservarla sana, podría apenas adoptarse parcialmente a un modelo agroproductivo guiado por el ánimo de lucro, para cuyos ejecutores únicamente importarían los beneficios productivos derivados de la aplicación de la técnica aprendida. Asunto sobre el cual los extensionistas rurales deberían ganar plena conciencia.

En este sentido, es también justo reconocer que preservar y favorecer el avance del conocimiento tradicional campesino va de la mano con los esfuerzos conducentes a conservar su cultura. Cultura muchas veces puesta en vilo por los modelos modernizadores de desarrollo, en mayoría orientadores de esquemas de cambio tecnológico que tratan de sobreponer, sobre cualquier otra, la agricultura industrial. Ante esta tendencia, es necesario tener presente que la cultura agrícola campesina cada vez más va perdiendo espacio en el mundo, cediendo frente a la naturalización de la cultura agrícola industrial (NÚÑEZ, 2004; DE MORAIS et al., 2009; HOEFLE, 2010). Ante el flujo unidireccional de innovaciones tecnológicas surgidas en los centros de investigación científica y transferidas por los extensionistas a los agricultores campesinos, los conocimientos y las prácticas locales se van difuminando 
y perdiendo, al ser condicionados, cuando no reemplazados, por nuevos saberes y prácticas culturales afines al modelo propagado.

Situación proclive a ser subvertida, como se ha expuesto hasta aquí, a partir del diálogo sinérgico e intercultural de saberes, base de un enfoque de extensión agrícola y rural que, en vez de tratar de homogeneizar el saber, integra los múltiples conocimientos existentes, así como a sus diversos portadores, en procura de complementariedades.

\section{Consideraciones finales}

En síntesis, el ejercicio realizado permite concluir que avanzar hacia la consolidación de una extensión rural fundada en el diálogo sinérgico de saberes demanda:

* Poner en diálogo las distintas perspectivas acerca de hacia dónde avanzar en términos de generar bienestar y mejores condiciones de existencia entre los miembros de las comunidades y sociedades campesinas. Acción que implica tener presente que la visión proyectada por las agencias de extensión no siempre coincide con los intereses y enfoques de las comunidades, hecho que convoca a concertar, desde el inicio, propósitos u objetivos compartidos sobre los cuales generar sinergias.

* Asumir que los miembros de las comunidades campesinas, sujetos con capacidad propositiva, argumentativa y de acción frente a sus propios problemas, han de ser actores claves en la concepción y planeación de los procesos y estrategias de desarrollo agrícola y rural. Vía diálogo de saberes, las partes involucradas, extensionistas y campesinos, en este caso, han de sumar conocimientos y experticias tras la búsqueda de soluciones concertadas a las problemáticas conjuntamente enfrentadas.

* Ganar conciencia acerca de que el diálogo suscitado entre campesinos y extensionistas es un diálogo entre expertos. Sujetos que, a pesar de haber logrado su experticia por caminos distintos, unos en la vida diaria y otros en las aulas, por ejemplo, pueden contribuir horizontalmente a proponer salidas a los problemas afrontados. En este caso, la complementación multidireccional de saberes sería la clave para la construcción conjunta.

* Reconocer la coexistencia de diversos sistemas de conocimientos (científico, campesino, tradicional, local, entre otros) que, en vez de negarse entre sí, pueden complementarse y articularse, contribuyendo con ello a ampliar el acervo cognitivo disponible para la resolución de problemas y el aprovechamiento de oportunidades.

Asociado a lo anterior, a manera de reflexión también crítica, vale mencionar que transitar de un modelo vertical de extensión a uno alternativo horizontal, fundado en el diálogo sinérgico de saberes, plantea varios retos a las instituciones que asumen la tarea de formar a los profesionales que ejercen como extensionistas 
rurales. Como se esbozó a lo largo del documento, uno de esos desafíos es aprender y enseñar a valorar a los miembros de las comunidades campesinas como sujetos portadores y productores permanentes de conocimientos aplicados. Acervo de saberes que, por encima de ser sustituido por el conocimiento occidental moderno, debería ser integrado al conjunto de instrumentos disponibles para la resolución de problemas contemporáneos. Integración que ha de hacerse en condiciones de horizontalidad, otorgándole al conocimiento campesino su debido estatus, poniéndolo a la altura del saber actualmente certificado por la ciencia y la racionalidad científica convencional.

En esta misma línea, parte del reto a asumir por las escuelas y facultades que brinda formación principalmente en ciencias agropecuarias es abrir sus fronteras a esos otros conocimientos. En espacios como éstos, en donde el pensamiento y la racionalidad científica se instituyen como el juicio delimitante entre lo que es o no es conocimiento, la apertura epistemológica a otras formas de conocer y concebir la realidad es una necesidad apremiante en aras del diálogo intercultural. En este caso, sin pretender disolver las diferencias efectivamente existentes, aprovechar las fortalezas de cada forma de conocimiento, en virtud de generar alternativas híbridas o nuevos conocimientos, sería el camino a seguir. Postura fundada en una noción de frontera (conocimiento científico/conocimiento campesino) que, en vez de separar, empalme o articule las distintas formas de conocimiento.

En este sentido, el diálogo sinérgico de saberes, acción que ha de dar pie al trabajo conjunto entre campesinos y extensionistas rurales alrededor de intereses u objetivos comunes, permitiría llegar a acuerdos y al diseño de estrategias (metodologías, prácticas, tecnologías) más próximas a la realidad vivida por las comunidades participes. Cotidianeidad de la cual se permearía dicha labor en equipo, dando como resultado respuestas más socioculturalmente aceptables y compatibles con las condiciones del medio en el que surgen.

Finalmente, otro desafío para las unidades formadoras es tomar críticamente distancia del paradigma modernizador predominante, usualmente orientador de los planes curriculares y las políticas de desarrollo agrícola y rural. En esta vía, concebir que la agricultura industrial-empresarial no es la única forma de agricultura existente, que con ésta conviven otras como la campesina, con propósitos, requerimientos y orientaciones distintas -especificidades que también hay que estudiar, enseñar e investigar-, haría parte de la lectura crítica. Análisis constructivo del que podrían derivar planes de formación más abiertos e incluyentes, conscientes de la diversidad agrícola y rural contemporánea, dispuestos a nutrirse de las diferencias que enriquecen.

\section{REFERENCIAS}

ALEMÁN, T. Vivir para conocer, conocer para vivir. A propósito de campesinos y científicos. Revista LEISA, v. 32, n. 1, p. 5-7, 2016.

ALEMANY, C.; SEVILLA-GUZMÁN, E. ¿Vuelve la extensión rural? Reflexiones y Propuestas agroecológicas vinculadas con el retorno y fortalecimiento de la extensión rural en América Latina. Buenos Aires: INTA. 2007. 
ALTIERI, M. Bases agroecológicas para una producción agrícola sustentable. Agricultura Técnica, v. 54, n. 4, p. 371- 386, 1994.

ALTIERI, M.; NICHOLLS, C. Los impactos del cambio climático sobre las comunidades campesinas y de agricultores tradicionales y sus respuestas adaptativas.

Agroecología, v. 3, p. 7-28, 2008.

ARNOLD, A. The Impact of the Educational System on Technological Change and Modernisation. In: HOSELITZ, B.F.; MOORE, W. E. (eds.). Industrialization and Society, Paris: UNESCO, 1996, p. 259-278.

BARKIN, D. La gestión popular del agua: respuestas locales freta a la globalización centralizadora. Ecología Política, n. 25, p. 22-33, 2003.

BELTRÁN, L. Adeus a Aristóteles: Comunicação horizontal. Comunicação e Sociedade, n. 6, p. 37-55, 1981.

BERNSTEIN, H. Modernization theory and the sociological study of development. The Journal of Development Studies, v. 7, n. 2, p. 141-160, 1971.

BORJA, J.; CASTILLO, J. La "agricultura bajo contrato": contribución al debate teórico. Ecuador: casos de maíz en Guayas, brócoli en Chimborazo y leche en Carchi. In: LACROIX, P.; PROAÑO, V. (eds.). Agricultura bajo contrato en el Ecuador: elementos para el debate. Quito: SIPAE, 2013, p. 31-64.

CÁCERES, D.; SILVETTI, F.; SOTO, G.; REBOLLEDO, W. La adopción tecnológica en sistemas agropecuarios de pequeños productores. Agro Sur, v. 24, n. 2, p. 123-135, 1997.

CALDERÓN, J.; LÓPEZ, D. Orlando Fals Borda y la Investigación Acción Participativa: aportes en el proceso de formación para la transformación. Buenos Aires: Centro Cultura de la Cooperación Floreal Gorini, 2013.

CAMARGO, F.; DE SOUZA, T.; DA COSTA, R. Etnoecologia e etnobotânica em ambientes de Cerrado no Estado de Mato Grosso. Interações, v. 15, n. 2, p. 356-360, 2014 .

CRUZ-LEÓN, A.; CERVANTES-HERRERA, J.; RAMÍREZ-GARCÍA, A.; SÁNCHEZ-GARCÍA, P.; DAMIÁN-HUATO, M; RAMÍREZ-VALVERDE, B. La etnoagronomía en la construcción de propuestas de desarrollo rural para comunidades rurales. Ra Ximhai, v. 11, n. 5, p. 185-194, 2015.

DE MORAIS, F.; DE MORAIS, R.; DA SILVA, C. Conhecimento ecológico tradicional sobre plantas cultivadas pelos pescadores da comunidade Estirão Comprido, Pantanal matogrossense, Brasil. Boletim do Museu Paraense Emílio Goeldi, v. 4, n. 2, p. 277-294, 2009. 
DELGADO, F. El diálogo intercultural e intercientífico: para el desarrollo endógeno sustentable y la reforma universitaria. Traspatios, n. 1, p. 62-27, 2006.

DELGADO, F.; RIST, S. Las ciencias desde la perspectiva del diálogo de saberes, la transdisciplinariedad y el diálogo intercientífico. In: DELGADO F.; RIST, S. (eds.). Ciencias, diálogo de saberes e interdisciplinariedad. Aporte teórico metodológico para la sustentabilidad alimentaria y el desarrollo. 1 ed. AGRUCO-UMSS, La Paz, 2016, p. 35-60.

DÍAZ, M.; ORTIZ, P.; NÚÑEZ, I. Interculturalidad, saberes campesinos y educación. Tlaxcala: El Colegio de Tlaxcala, 2005.

FALS BORDA, O.; y BRANDÃO, C. 1987. Investigación Participativa. Montevideo: La Banda Oriental, 1987.

FALS BORDA, O.; ANISUR, M. Acción y conocimiento: rompiendo el monopolio con la IAP. Bogotá: Rahman, 1991.

FERNÁNDEZ, H.; PÉREZ, L.; GODOY, S.; REYES, A.; VALDÉS, V. Programa de extensionismo agropecuario de la Secretaría de Fomento Agropecuario del Gobierno del estado de Coahuila. Revista Mexicana de Agronegocios, v. 24, p. 734$743,2009$.

FIGUEROA-RODRÍGUEZ, B.; FIGUEROA-RODRÍGUEZ, K.; DE LOS RÍOS-CARMENAD, I.; FIGUEROA-SANDOVAL, B.; HERNÁNDEZ-ROJAS, F. 2010. La empresarialidad en prestadores de servicios profesionales agropecuarios en el estado de Campeche, México. Ra Ximhai, v. 6. n. 3, p. 355-364, 2010.

FREIRE, P. ¿Extensión o comunicación? La concientización en el medio rural. México: Siglo XXI, 1973.

FREIRE, P.; FAUNDEZ, A. Por una pedagogía de la pregunta. Río de Janeiro: Paz y Tierra, 1985.

FUENTES, R. Everett M. Rogers (1931-2004) y la investigación latinoamericana de la comunicación. Nueva época, n. 4, 93-125, 2005.

GIRALDO, F. Campesinas construyendo la utopía: mujeres, organizaciones y agroindustrias rurales. Cuadernos de desarrollo rural, v. 7, n. 65, p. 43-61, 2010.

GLIESSMAN, S. Agroecology. Ecological Processes in Sustainable Agriculture. Santa Cruz: Sleeping Bear Press, 1998.

HOEFLE, S. Ética ambiental, sistema agrícola e paisagem cultural na Mata Atlântica no Sudeste Brasileiro. Ateliê Geográfico, v. 3, n. 3, p. 22-52, 2009. 
KRÖHLING, C. Escuelas Latinoamericana de Comunicación: conribuciones de Luis Ramiro Beltrán. In: BELTRÁN, R. (org.). Investigaciones sobre comunicación en latinoamerica. Inicio, trascendencia y proyección. La Paz: Plural, 2000, p. 155-166.

LELIS, D.; COELHO, F.; DIAS, M. A necessidade das intervenções: Extensão Rural como serviço ou como direito? Interações, v. 13, n. 1, 69-80, 2012.

LERNER, D. The passing of traditional society: Modernizing the Middle East. Illinois: The Free Press, 1958.

LIMIA, D. Construcción del poder desde abajo. Revista Ciencia, Innovación y Desarrollo, v.9, n. 2, p. 52-57, 2004.

LONG, A.; VAN DER PLOEG, J. Endogeonus Development: Practices and Perspectives. In: PLOEG, J.; LONG, A. (orgs.). Born from within: Practices and Perspectives of Endogenous Rural Development. Assen: Van Gorcum, 1994, p. 1-16.

MÉNDEZ, M. El rol social de la extesión rural: enfoques para una intervención interdisciplinaria. Revista de Educação Técnica e Tecnológica em Ciências Agrícolas, v 7, n. 4, p. 32-48, 2016.

MURGA, A.; BOLIS, G. 1979. Sociedad y ciencia social en Latinoamérica. In: MURGA, A.; BOLIS, G. (eds.). Las ciencias sociales en América Latina. México: UNAM, 1979, p. 9-31.

NISHIKAWA, J. Cadenas productivas promisorias para la seguridad alimentaria e inclusión económica en familias pobres rurales. Tesis de Maestría. Pontificia Universidad Católica del Perú, Lima, 2016.

NORGAARD, R. Development Betrayed: The end of Progress and a Coevolutionary Revisiting of the Future. London: Routledge, 1994.

NÚNEZ, J. Los saberes campesinos: implicaciones para una educación rural. Investigación y Postgrado, v. 19, n. 2, p. 1-19, 2004.

PANIZO, M.; PERDOMO, A. Recopilando y compartiendo el Conocimiento Ecológico Tradicional. Revista Agroecológica de Divulgación, n. 28, p. 52-54, 2017.

PARDO, L. EI SERVAS, una herramienta de extensionismo agrícola para la UBPC “Rigoberto Corcho". Tesis de Maestría. Universidad de La Habana. La Habana, 2008.

PAVÓN, M. Extensionismo en Cuba: Estudios de caso. Cultivos Tropicales, v. 35, n. 1, p. 5-10, 2014.

PEÑARANDA, G. Análisis del sector agropecuario Colombiano en el contexto de la problematica social Latinoamericana. Revista FACE, v. 10, n. 1, p. 227-240, 2010. 
PÉREZ, M.; ARGUETA, A. Saberes indígenas y dialogo intercultural. Cultura y Representaciones Sociales, v. 5, n. 10, p. 31-56, 2011.

PIMENTEL-EQUIHUA, J.; VELÁZQUEZ-MACHUCA, M.; PALERM-VIQUEIRA, J. Capacidades locales y de gestión social para el abasto de agua doméstica en comunidades rurales del Valle de Zamora, Michoacán, México. Agricultura, Sociedad y Desarrollo, v. 9, n. 2, p. 107-121, 2012.

RODRÍGUEZ, L.; LA O, M.; FONSECA, M.; GUEVARA, F.; HERNÁNDEZ, A.; JIMÉNEZ, M. Extensionismo o innovación como proceso de aprendizaje social y colectivo. ¿Dónde está el dilema? Revista Cubana de Ciencia Agrícola, v. 43, n. 4, p. 387-394, 2009.

RODRÍGUEZ, L.; MARIN, C.; MORENO, Si.; RUBANO, M. Paulo Freire: una pedagogía desde América Latina. Ciencia, Docencia y Tecnología, v. 18, n. 34, p. 129-171, 2007.

RODRÍGUEZ-MORENO, J. Elementos de la praxis y del corpus del conocimiento etnoecológico tzeltal en comunidades de la Sierra Norte de Chiapas. Revista LiminaR, v. 12, n. 1, p. 92-102, 2014.

ROGERS, E. Diffusion of Innovations. New York: The Free Press of Glencoe, 1962.

ROGERS, E. Diffusion of innovations in rural societies. Michigan: Michigan State University, 1964.

SAMPER, M. 2005. Redes sociales y comunicación entre experimentadores campesinos en Puriscal, Costa Rica. Revista Ciencias Sociales, v. 4, n. 106, p. 143-163, 2005 .

SEVILLA-GUZMÁN, E. Uma estratégia de sustentabilidade a partir da agroecologia. Agroecologia e Desenvolvimento Rural Sustentável, v. 2, n. 1, p. 35-45, 2001.

SEVILLA-GUZMÁN, E.; WOODGATE, G. Sustainable rural development: from industrial agriculture to agroecology. In: REDCLIFT, M.; WOODGATE, G. (eds.). The International Handbook of Environmental Sociology. Madrid: Mc. Graw Hill, 1998, p. 83-100.

TAPIA, N. Agroecología y agricultura campesina sostenible en los Andes bolivianos. La Paz: AGRUCO-PLURAL, 2006.

TAPIA, N. El diálogo de saberes y la investigación participativa revalorizadora: Contribuciones y desafios del desarrollo sustentable. In: DELGADO, F. (org.). Ciencias, diálogo de saberes y transdisciplinariedad. Aportes teórico metodológicos para la sustentabilidad alimentaria y del desarrollo. La Paz: AGRUCO, 2016, p. 89-119. 
TOBASURA, I. Extensión rural: de la difusión de innovaciones a la mediación participativa. In: SEMINARIO INTERNACIONAL Y ENCUENTRO NACIONAL DE EXTENSIÓN RURAL, 3., 2018, Manizales. Memorias... Manizales: RENER-Universidad de Caldas, 2018, p. 16-26.

TOLEDO, V. La memoria tradicional: la importancia agroecológica de los saberes locales. Revista LEISA, v. 20, n. 4, p. 16-19, 2005.

TOMMASINO, H.; GONZÁLEZ, M.; GUEDES, E.; PRIETO, M. 2006. Extensión crítica: los aportes de Paulo Freire. In: TOMMASINO, H.; De HEGEDÜS, P. (eds.). Extensión: reflexiones para la intervención en el medio urbano y rural. Montevideo:

Universidad de la República, 2006, p. 121-135.

Marlon Javier Méndez Sastoque. Doctor en Desarrollo, Agricultura y Sociedad (UFRRJ, Brasil). Magister en Sociología Rural (Universidad Autónoma Chapingo, México). Magister en Desarrollo Rural (Pontificia Universidad Javeriana, Colombia). Ingeniero Agrónomo (Universidad Nacional de Colombia, Bogotá). Docente adscrito al Departamento de Desarrollo Rural y Recursos Naturales, Facultad de Ciencias Agropecuarias, de la Universidad de Caldas, Manizales, Colombia.marlon.mendez@ucaldas.edu.co

Como citar: SASTOQUE, Marlon Javier Méndez. Rumo a uma extensão rural baseada no diálogo sinérgico de saberes: agricultores e extensionistas construindo juntos. Redes (St. Cruz Sul, Online), Santa Cruz do Sul, v. 25, n. 1, jan. 2020. ISSN 1982-6745. DOI: https://doi.org/10.17058/redes.v25i1.14684. 